\title{
Oxidation of Olefins Using Rhenium Supported by Imidazole-Functionalized Amphiphilic Copolymers
}

\author{
Sheng-Hsuan Wei · Shiuh-Tzung Liu
}

Received: 12 August 2008/Accepted: 10 September 2008/Published online: 7 October 2008

(C) Springer Science+Business Media, LLC 2008

\begin{abstract}
Well-defined amphiphilic $\mathrm{EO}_{45}-\mathrm{b}-\mathrm{MA}_{\mathrm{m}}$ block copolymers modified with aminopropyl-imidazole groups are used as a support for methyltrioxorhenium. This material appears to be a good catalyst for the oxidation of olefins into the corresponding diols and can be recycle-used.
\end{abstract}

Keywords Oxidation of olefin - Amphiphilic block copolymer $\cdot$ Recycle catalyst $\cdot$ Rhenium

\section{Introduction}

The use of micelle systems, which are capable of dissolving organic molecules in water, in obtaining product formation has received much attention and provokes chemist to examine the potential micelles as reaction media $[1,2]$. In this context, it has been demonstrated that polymer supports undergo self-assemble in water to form micellar aggregates with a hydrophobic environment providing reactivity better than conventional micelles based on small molecule surfactant [1, 2]. Soluble polymeric supports involve polystyrene, poly(ethylene glycol), and dendritic/hyperbranched polymers [3-7].

In our previous work, we have found that polymers of poly (ethylene glycol)-b-(methyl acrylate) [denoted as $\mathrm{EO}_{\mathrm{n}}$ b- $\mathrm{MA}_{\mathrm{m}}$ ] are excellent agents to form uniformly micellar aggregates in water with a hydrophobic core and watersoluble shell, thus templating the synthesis of mesoporous silicas [8-10]. Inspired by polymer-support catalysis, we

S.-H. Wei · S.-T. Liu $(\bowtie)$

Department of Chemistry, National Taiwan University,

Taipei 106, Taiwan, ROC

e-mail: stliu@ntu.edu.tw intended to use $\mathrm{EO}_{\mathrm{n}}-\mathrm{b}-\mathrm{MA}_{\mathrm{m}}$ for preparation of a core-shelltype nano-reactor where the hydrophobic core provides a favorable environment for the metal complex and the reactant, while the hydrophilic shell allows these reactors to be water soluble. Here we describe the preparation of welldefined amphiphilic copolymers $\left(\mathrm{EO}_{\mathrm{n}}-\mathrm{b}-\mathrm{MA}_{\mathrm{m}}\right)$ with imidazole units covalently attached to the polymer. The rhenium complexes with this copolymer are studied for the aqueous two-phase oxidation of alkenes.

\section{Experimental}

All reaction steps for polymerization were performed under a dry nitrogen atmosphere. Dichoromethane was dried with $\mathrm{CaH}_{2}$ and distilled under nitrogen. $\left[\mathrm{CH}_{3}\left(\mathrm{OCH}_{2} \mathrm{CH}_{2}\right)_{45}\right.$ $\left.\mathrm{NH}_{2}\right], \mathrm{N}\left[\mathrm{CH}_{2} \mathrm{CH}_{2} \mathrm{~N}\left(\mathrm{CH}_{3}\right)_{2}\right]_{3}$ (Metren), and macro-initiator MI were prepared according to the method reported in literature [10]. Nuclear magnetic resonance spectra were recorded on a Bruker AVANCE 400 spectrometer. Infrared spectra were measured on a Nicolet Magna-IR 550 spectrometer (Series-II) as $\mathrm{KBr}$ pallets. Gel permeation chromatography (GPC) data were obtained from a Waters Model 590 liquid chromatograph installed with a Lab Allience RI 2000 detector using THF as eluant (at the rate $1 \mathrm{~mL} / \mathrm{min}$ ) at $40{ }^{\circ} \mathrm{C}$ and polystyrene calibration curve for analyses.

\subsection{Synthesis and Characterization (Scheme 1)}

\subsubsection{Diblock Copolymer $\left(E_{45}-b-M A_{m}\right)$}

A mixture of MI (5.0 g, $2.3 \mathrm{mmol})$ and $\mathrm{CuBr}$ (85 mg, $0.46 \mathrm{mmol}$ ) was placed in a $50 \mathrm{~mL}$ flask sealed with a septum. The flask was evacuated and flashed with nitrogen 
Scheme 1

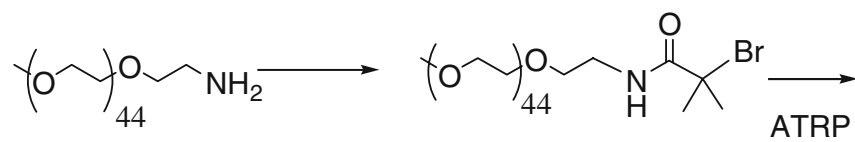

MI

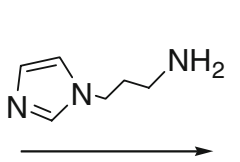

$\mathrm{EO}_{45}-\mathrm{b}-\mathrm{MA}_{\mathrm{m}}-\mathrm{I}$<smiles>COC(=O)C(C)(C)CC(C)(C)C(=O)NC(C)(C)CCOC(C)(C)C</smiles>

$\mathrm{EO}_{45}-\mathrm{b}-\mathrm{MA} \mathrm{A}_{\mathrm{m}}$ three times. Methyl acrylate $(15.5 \mathrm{~mL}, 173 \mathrm{mmol})$ was syringed into the above mixture with stirring. Metren $(175 \mu \mathrm{L}, 0.46 \mathrm{mmol})$ was then added and the polymerization took place immediately. After stirring $30 \mathrm{~min}$, the reaction was quenched by the addition of THF $(30 \mathrm{~mL})$. The reaction mixture was filtered through silica gel to remove the catalyst. Upon concentration and re-precipitation in ether/methanol, the obtained copolymer was dried under vacuum overnight (19.3 g, 99\%). ${ }^{1} \mathrm{H} \quad \mathrm{NMR}$ $\left(400 \mathrm{MHz}, \mathrm{CDCl}_{3}\right) \delta 3.82-3.60\left(255 \mathrm{H}, \mathrm{br},-\mathrm{OCH}_{3}\right), 3.62$ (180 H, br, $-\mathrm{OCH}_{2} \mathrm{CH}_{2}-$ ), $3.40\left(\mathrm{~s}, 3 \mathrm{H},-\mathrm{OCH}_{3}\right), 2.40-2.20$ $\left(85 \mathrm{H}, \mathrm{br},-\mathrm{CHCH}_{2}\right), 2.00-1.40\left(170 \mathrm{H}, \mathrm{br},-\mathrm{CH}-\mathrm{CH}_{2}-\right)$, $1.14\left(3 \mathrm{H}, \mathrm{s},-\mathrm{C}\left(\mathrm{CH}_{3}\right)_{2}\right), 1.12\left(3 \mathrm{H}, \mathrm{s},-\mathrm{C}\left(\mathrm{CH}_{3}\right)_{2}\right)$. GPC: $\mathrm{M}_{\mathrm{N}}=9,800$, PDI $=1.13 . \mathrm{IR}(\mathrm{KBr}): 1,744 \mathrm{~cm}^{-1}\left(v_{\mathrm{C}=\mathrm{O}}\right)$.

\subsubsection{Modification of Copolymer $\left(E_{45}-b-M A_{85}-I\right)$}

A mixture of $\mathrm{EO}_{45}-\mathrm{b}-\mathrm{MA}_{85}(1.0 \mathrm{~g}, 0.12 \mathrm{mmol})$ and $\mathrm{N}$-(3aminopropyl)imidazole $(1 \mathrm{~mL})$ was heated at $140{ }^{\circ} \mathrm{C}$ for 20 h. Excess of imidazole was removed under vacuum and the residue was dissolved in methanol. Addition of THF to the above solution gave the desired product as white precipitates (1.21 g). ${ }^{1} \mathrm{H}$ NMR (400 MHz, $\left.\mathrm{D}_{2} \mathrm{O}\right) \delta 8.20-7.60$ (br, $85 \mathrm{H}$, imidazole-H), 7.40-7.00 (br, $170 \mathrm{H}$, imidazole$\mathrm{H}$ ), 4.22-4.00 (br, $170 \mathrm{H},-\mathrm{N}-\mathrm{CH}_{2}-$ ), 3.80-3.50 (br, 180 $\left.\mathrm{H}, \mathrm{OCH}_{2} \mathrm{CH}_{2}-\right), 3.40\left(3 \mathrm{H},-\mathrm{OCH}_{3}\right), 3.30-2.95$ (br, $255 \mathrm{H}$, $-\mathrm{CONCH}_{2}-$ and $\left.\mathrm{CO}-\mathrm{CH}-\mathrm{CH}_{2}-\right), 1.80-1.15(170 \mathrm{H}$, $\left.-\mathrm{CH}-\mathrm{CH}_{2}-\right)$. IR: (KBr) $3,481 \mathrm{~cm}^{-1}\left(v_{\mathrm{N}-\mathrm{H}}\right), 1,652 \mathrm{~cm}^{-1}$ $\left(v_{\mathrm{C}=\mathrm{O}}\right), 1,552 \mathrm{~cm}^{-1}\left(v_{\mathrm{C}=\mathrm{N}}\right.$, imidazole $)$.

\subsubsection{Preparation of $\mathrm{EO}_{45}-\mathrm{b}-\mathrm{MA} \mathrm{A}_{85}-\mathrm{Re}$}

To a solution of $\mathrm{EO}_{45}-\mathrm{b}-\mathrm{MA}_{85}-\mathrm{I}(50 \mathrm{mg})$ in ethanol $(5 \mathrm{~mL})$ was added a solution of $\mathrm{MeReO}_{3}(30 \mathrm{mg}, 0.12 \mathrm{mmol})$ in $0.5 \mathrm{~mL}$ of ethanol. The resulting mixture was stirred at room temperature for several hours. Yellow-brown color precipitation was deposited on the flask, which was obtained by filtration. This solid was washed with ethanol and ether several times and then dried under vacuum for $2 \mathrm{~h}$. By the analysis of ICP Mass, per gram of this material contained $164 \mathrm{mg}$ of Re. IR $3,481 \mathrm{~cm}^{-1}\left(v_{\mathrm{N}-\mathrm{H}}\right), 1649 \mathrm{~cm}^{-1}\left(v_{\mathrm{C}=\mathrm{O}}\right)$, $1,548 \mathrm{~cm}^{-1}\left(v_{\mathrm{C}=\mathrm{N}}\right.$, imidazole $), 912 \mathrm{~cm}^{-1}\left(v_{\mathrm{Re}=\mathrm{O}}\right)$.

\subsection{Catalysis}

\subsubsection{Typical Procedure for Oxidation of Cyclohexene}

A mixture of cyclohexene (5 mmol), $\mathrm{KHSO}_{5}(10 \mathrm{mmol})$, and $\mathrm{EO}_{45}$-b-MA $\mathrm{M}_{8}-\mathrm{Re}$ in a mixture of ethyl acetate/water $(1: 1,20 \mathrm{~mL})$ was stirred at room temperature for $12 \mathrm{~h}$. The reaction was monitored by GC analysis to check the consume of reactant. Upon standing for $12 \mathrm{~h}$, the organic product was obtained by separartion of organic layer. The organic portions was dried and concentrated. Product analysis was performed by $\mathrm{GC}$ and ${ }^{1} \mathrm{H}$ NMR spectroscopic methods. ${ }^{13} \mathrm{C}$ NMR $\left(100 \mathrm{MHz}, \mathrm{CDCl}_{3}\right) \delta 75.6,33.0$ and $24.4 \mathrm{ppm}$, which are all essentially identical to those reported for trans-cyclohexanediol [14].

\subsubsection{Recycle Use of Catalyst}

A mixture of cyclohexene (5 mmol), $\mathrm{KHSO}_{5}(10 \mathrm{mmol})$, and $\mathrm{EO}_{45}-\mathrm{b}-\mathrm{MA}_{85}-\mathrm{Re}$ in a mixture of ethyl acetate/water $(1: 1,20 \mathrm{~mL})$ was stirred at room temperature for $12 \mathrm{~h}$. Upon the separation of organic layer, the aqueous portion was added to a mixture of cyclohexene $(5 \mathrm{mmol})$ and $\mathrm{KHSO}_{5}(10 \mathrm{mmol})$ in ethyl acetate $(10 \mathrm{~mL})$. The resulting mixture was stirred for another run.

\section{Results and Discussion}

The synthesis of linear diblock copolymers $\left(\mathrm{EO}_{44}-\mathrm{b}-\mathrm{MA}_{\mathrm{m}}\right)$ has been accomplished by using the ATRP (Atom transfer 
Table 1 Preparation of diblock copolymers ${ }^{\mathrm{a}}$

\begin{tabular}{lllll}
\hline Entry & {$[\mathrm{MA}] /[\mathrm{MI}]$} & $\mathrm{M}_{\mathrm{N}}$ & PDI & EO:MA $^{\mathrm{b}}$ \\
\hline 1 & 85 & 9800 & 1.13 & $45: 82$ \\
2 & 45 & 6100 & 1.15 & $45: 44$ \\
3 & 30 & 4800 & 1.14 & $45: 30$ \\
\hline
\end{tabular}

${ }^{a}$ Reaction conditions: MI $(2.3 \mathrm{mmol}), \quad\left[\left(\mathrm{Me}_{2} \mathrm{NCH}_{2} \mathrm{CH}_{2}\right)_{3} \mathrm{~N}\right]$ $(0.46 \mathrm{mmol}), \mathrm{CuBr}(0.46 \mathrm{mmol})$ and monomer at room temperature

b Units of EO versus MA

radical polymerization) method [10]. Preparation of the functionalized copolymer is summarized in scheme 1. Macro-initiator (MI), which obtained from the condensation of $\mathrm{CH}_{3}\left(\mathrm{OCH}_{2} \mathrm{CH}_{2}\right)_{45} \mathrm{NH}_{2}$ with 2-bromoisobutyryl bromide, was subjected to connect the poly(methyl acrylate) chain by the ATRP [11]. A typical procedure is as follows: a mixture of $\mathrm{MI}, \mathrm{CuBr}(20 \mathrm{~mol} \%)$ and methyl acrylate (MA) forming a homogeneous solution in a $25 \mathrm{~mL}$ flask was degassed. $\left[\left(\mathrm{Me}_{2} \mathrm{NCH}_{2} \mathrm{CH}_{2}\right)_{3} \mathrm{~N}\right](20 \mathrm{~mol} \%)$ was then added. After stirring at room temperature for $1 \mathrm{~h}$, the reaction mixture was diluted with THF. The reaction mixture was passed through silica gel to remove the copper complexes. The filtrate was concentrated to give the desired polymer. By manipulation molar ratio of $[\mathbf{M I}] /$ [monomer], a series of polymers $\mathrm{EO}_{45} \mathrm{MA}_{\mathrm{m}}$ with different chain length of poly-acrylate were obtained (Table 1).

Based on the GPC and ${ }^{1} \mathrm{H}$ NMR integration, the polymerization degree of MA is estimated, which is consistent with the molar ratio of monomers in the reaction (Table 1). In all instances, all monomers were completely converted into polymers. Infrared spectrum of the copolymer shows a characteristic absorption at $1,744 \mathrm{~cm}^{-1}$ for the carbonyl stretching of acrylate. Under refluxing conditions, treatment of $\mathrm{EO}_{45}$-b-MA $\mathrm{MA}_{\mathrm{m}}$ with excess of 1-(3-aminopropyl)imidazole yielded the imidazole-bound copolymers $\left(\mathrm{EO}_{45} \mathrm{~b}\right.$ $\left.\mathrm{MA}_{\mathrm{m}}-\mathrm{I}\right)$. The infrared spectrum of $\mathrm{EO}_{45}-\mathrm{b}-\mathrm{MA}_{\mathrm{m}} \mathrm{-I}$ presents a distinctive carbonyl stretching at $1,648 \mathrm{~cm}^{-1}$ with the diminishing peak at $1744 \mathrm{~cm}^{-1}$, indicating that all ester functionalities of the copolymer are converted into the amide linkage. In addition, the ${ }^{1} \mathrm{H}$ NMR spectrum of $\mathrm{EO}_{45^{-}}$ b-MA ${ }_{85}$-I shows that signals of all methyl groups corresponding to methyl ester are disappeared accompanied with the new shifts at 7.0-7.4 (br) and 7.6-8.2 (br) for the imidazole-hydrogens. Both spectral data are consistent with the formation of the desired functionalized copolymers.

Complexation of rhenium oxide with $\mathrm{EO}_{45}-\mathrm{b}-\mathrm{MA}_{\mathrm{m}}-\mathrm{I}$ was achieved by mixing the polymer $\mathrm{EO}_{45}-\mathrm{b}-\mathrm{MA}_{85}$ and methyltrioxorhenium in ethanol solution. The obtained material $\left(\mathrm{EO}_{45}-\mathrm{b}-\mathrm{MA}_{85}-\mathrm{Re}\right)$ is a light brown powder solid. Analysis of IR spectra of $\mathrm{EO}_{45}-\mathrm{b}-\mathrm{MA}_{85}-\mathrm{Re}$ confirms the coordination of imidazole toward metal ions due to the presence of the expected $\mathrm{C}=\mathrm{N}$ stretching at $1,548 \mathrm{~cm}^{-1}$.
The loading level of metal ions is determined to be $164 \mathrm{mg}$ per gram of polymer via the ICP Mass analysis. Further evidence for the formation of rhenium complex with imidazole comes from the Raman bands. Raman spectrum of $\mathrm{EO}_{45}$-b-MA $\mathrm{MA}_{85}$ - Re shows the band corresponding to the asymmetric $\mathrm{Re}=\mathrm{O}$ stretching vibrations at $912 \mathrm{~cm}^{-1}$, which is similar to that for $\mathrm{CH}_{3} \mathrm{ReO}_{3}(\mathrm{~N}-\mathrm{N})$ [12].

To check the potency of $\mathrm{EO}_{45}-\mathrm{b}-\mathrm{MA}_{85}$ - Re for the oxidation reaction, cyclohexene was treated with oxidants in aqueous two-phase at room temperature (Table 2). It is quite obvious that the oxidation proceeds smoothly under phase-transfer conditions, better than in an organic solvent. Without the use of surfactants (CTAB), $\mathrm{MeReO}_{3}$ does not show good catalytic activity on the oxidation (entry 2 versus 3). Obviously, the good activity of the $\mathrm{EO}_{45}$-b$\mathrm{MA}_{85}$-Re is because of the amphiphilic supporting and the imidazole ligand accelerated catalysis. From NMR spectroscopy, the product obtained is the 1,2-cyclohexanediol instead of the epoxide. The ${ }^{13} \mathrm{C}$ shifts of the diol product shows $\delta 75.6,33.0$ and $24.4 \mathrm{ppm}$, which are consistent with the trans-isomer [13]. Apparently, this catalytic reaction provides the epoxide as the initial product, which is subsequently hydrolyzed into the trans-diol. This result is quite different from the work reported by Saladino and coworkers [14]. They reported that microencapsulated Lewis base adduct of $\mathrm{MeReO}_{3}$ with amine ligands was an efficient catalyst for the epoxidation of olefins in organic solvent. However, we learned that the catalytic system in our study was quite acidic and $\mathrm{pH}$ value reached up to $2-3$, which might explain the production of the diol instead of the epoxide.

To optimize the reaction conditions, the oxidation reactions were performed under various conditions using at $\mathrm{EO}_{45}$-b- $\mathrm{MA}_{85}-\mathrm{Re}$. Both $\mathrm{CH}_{2} \mathrm{Cl}_{2} /$ water and ethyl acetate/ water are good solvent systems for carrying out the oxidation (Table 2, entries 5 and 7). Higher oxidation yields were obtained with ethyl acetate and dichloromethane because they are good solvents for reactants and diffuse easily in the polymer. However, the use of hexane/water as the solvents leads the failure of the catalysis, which might be due to the insoluble nature of the polymer in hexane.

The ability of different oxidants such as $\mathrm{O}_{2}, \mathrm{H}_{2} \mathrm{O}_{2}$, $\mathrm{KHSO}_{5}$ and urea- $\mathrm{H}_{2} \mathrm{O}_{2}$ (UHP) was examined in the oxidation of cyclohexene at room temperature. The results showed that in the presence of $\mathrm{EO}_{45}-\mathrm{b}-\mathrm{MA}_{85}$-Re catalyst, $\mathrm{KHSO}_{5}$ was the best oxygen source due to good oxidation conversions. Other oxidants in ethyl acetate/water did not show any good activity. The temperature effect was less pronounced as observed from conversions of $45 \%$ at room temperature, $44 \%$ at $40{ }^{\circ} \mathrm{C}$ and $46 \% \mathrm{C}$ at $60{ }^{\circ} \mathrm{C}$.

In view of the above results, the catalytic system renders the best yield in oxidation of cyclohexene into trans-1,2cyclohexanediol and was followed in the subsequent 
Table 2 Results of the oxidation of cyclohexene in the presence of $\mathrm{CH}_{3} \mathrm{ReO}_{3}{ }^{\mathrm{a}}$

\begin{tabular}{|c|c|c|c|c|c|c|c|c|}
\hline Entry & Catalyst & Oxidant & Solvent & $\mathrm{T}\left({ }^{\circ} \mathrm{C}\right)$ & $\mathrm{t}(\mathrm{h})$ & Conv. $(\%)^{\mathrm{b}}$ & Yield $(\%)^{\mathrm{c}}$ & $\mathrm{TON}^{\mathrm{d}}$ \\
\hline 1 & None & $\mathrm{KHSO}_{5}$ & $\mathrm{EA} / \mathrm{H}_{2} \mathrm{O}$ & $\mathrm{rt}$ & 24 & 7 & 7 & 80 \\
\hline 2 & $\mathrm{CH}_{3} \mathrm{ReO}_{3}$ & $\mathrm{KHSO}_{5}$ & $\mathrm{EA} / \mathrm{H}_{2} \mathrm{O}$ & $\mathrm{rt}$ & 12 & 45 & 45 & 513 \\
\hline 3 & $\mathrm{CH}_{3} \mathrm{ReO}_{3} / \mathrm{CTAB}^{\mathrm{e}}$ & $\mathrm{KHSO}_{5}$ & $\mathrm{EA} / \mathrm{H}_{2} \mathrm{O}$ & $\mathrm{rt}$ & 12 & 100 & 100 & 1140 \\
\hline 4 & $\mathrm{EO}_{45} \mathrm{MA}_{85}-\mathrm{Re}$ & $\mathrm{KHSO}_{5}$ & $\mathrm{EA} / \mathrm{H}_{2} \mathrm{O}$ & $\mathrm{rt}$ & 5 & 45 & 44 & 502 \\
\hline 5 & $\mathrm{EO}_{45} \mathrm{MA}_{85}-\mathrm{Re}$ & $\mathrm{KHSO}_{5}$ & $\mathrm{EA} / \mathrm{H}_{2} \mathrm{O}$ & $\mathrm{rt}$ & 12 & 100 & 100 & 1140 \\
\hline 6 & $\mathrm{EO}_{45} \mathrm{MA}_{85}-\mathrm{Re}$ & $\mathrm{KHSO}_{5}$ & Ether/ $\mathrm{H}_{2} \mathrm{O}$ & $\mathrm{rt}$ & 48 & 34 & 33 & 376 \\
\hline 7 & $\mathrm{EO}_{45} \mathrm{MA}_{85}-\mathrm{Re}$ & $\mathrm{KHSO}_{5}$ & $\mathrm{CH}_{2} \mathrm{Cl}_{2} / \mathrm{H}_{2} \mathrm{O}$ & $\mathrm{rt}$ & 12 & 100 & 100 & 1140 \\
\hline 8 & $\mathrm{EO}_{45} \mathrm{MA}_{85}-\mathrm{Re}$ & $\mathrm{KHSO}_{5}$ & Hexane/ $\mathrm{H}_{2} \mathrm{O}$ & $\mathrm{rt}$ & 48 & 0 & - & - \\
\hline 9 & $\mathrm{EO}_{45} \mathrm{MA}_{85}-\mathrm{Re}$ & $\mathrm{KHSO}_{5}$ & $\mathrm{EA} / \mathrm{H}_{2} \mathrm{O}$ & $40{ }^{\circ} \mathrm{C}$ & 5 & 44 & 43 & 490 \\
\hline 10 & $\mathrm{EO}_{45} \mathrm{MA}_{85}-\mathrm{Re}$ & $\mathrm{KHSO}_{5}$ & $\mathrm{EA} / \mathrm{H}_{2} \mathrm{O}$ & $60{ }^{\circ} \mathrm{C}$ & 5 & 46 & 46 & 524 \\
\hline 11 & $\mathrm{EO}_{45} \mathrm{MA}_{85}-\mathrm{Re}$ & $\mathrm{O}_{2}$ & $\mathrm{EA} / \mathrm{H}_{2} \mathrm{O}$ & $\mathrm{rt}$ & 48 & 0 & - & - \\
\hline 12 & $\mathrm{EO}_{45} \mathrm{MA}_{85}-\mathrm{Re}$ & $\mathrm{H}_{2} \mathrm{O}_{2}$ & $\mathrm{EA} / \mathrm{H}_{2} \mathrm{O}$ & $\mathrm{rt}$ & 12 & 30 & - & - \\
\hline 13 & $\mathrm{EO}_{45} \mathrm{MA}_{85}-\mathrm{Re}$ & UHP & $\mathrm{EA} / \mathrm{H}_{2} \mathrm{O}$ & $\mathrm{rt}$ & 48 & 30 & - & - \\
\hline
\end{tabular}

a Reaction conditions: cyclohexene $(5 \mathrm{mmol})$, catalyst $(5 \mathrm{mg})$ and oxidant $(10 \mathrm{mmol})$ in solvent (10 mL; 1:1 by volume). [cyclohexene]:[Re] $=1,140$

${ }^{\mathrm{b}}$ Determined by GC

c trans-1,2-Cyclohexanediol; yield based on NMR integration with mesitylene as the internal standard in $\mathrm{CDCl}_{3}$

d $\mathrm{TON}=$ per mol product/per mol Re catalyst

e $\mathrm{CTAB}=$ Cetyltrimethylammonium bromide

Table 3 Conversion of alkenes into its corresponding diol ${ }^{\mathrm{a}}$

\begin{tabular}{lllrr}
\hline Entry & Alkenes & Solvents & Time $(\mathrm{h})$ & Yield $(\%)^{\text {TON }^{\mathrm{d}}}$ \\
\hline 1 & 1-methylcyclohexene & EA/water & 5 & 100 \\
2 & 1-methylcyclohexene & $\mathrm{CH}_{2} \mathrm{Cl}_{2} /$ water & 5 & 96 \\
3 & 1-acetylcyclohexene & EA/water & 5 & - \\
4 & 4-vinylcyclohexene & EA/water & 12 & $86^{\mathrm{b}}$ \\
5 & 1-ethynylcyclohexene & EA/water & 24 & 85 \\
6 & Limonene & EA/water & 48 & $62^{\mathrm{c}}$ \\
7 & Styrene & EA/water & 48 & 79 \\
8 & Cyclooctene & $\mathrm{CH}_{2} \mathrm{Cl} /$ water & 48 & 870 \\
9 & 1-hexene & EA/water & 12 & 900 \\
\hline
\end{tabular}

${ }^{a}$ Reaction conditions: olefin $(5 \mathrm{mmol}), \mathrm{KHSO}_{5}(10 \mathrm{mmol})$, catalyst $(5 \mathrm{mg})$, solvent $(10 \mathrm{~mL})$ and water $(10 \mathrm{~mL})$ at room temperature.[alkene]:[catalyst] $=1,140$

b 4-vinylcyclohexane-1,2-diol as the product

c 4-isopropenyl-1-methyl-cyclohexane-1,2-diol as the product

d $\mathrm{TON}=$ per mol product/per mol Re catalyst

studies. Various substituted olefins are tested under this reaction conditions and the results are summarized in Table 3. Substituted cyclohexenes when reacted with $\mathrm{KHSO}_{5}$ via the $\mathrm{EO}_{45}-\mathrm{b}-\mathrm{MA}_{85}-\mathrm{Re}$ catalyst afforded the corresponding diol in excellent yields except 1-acetylcyclohexene (entries 1-6). Under the reaction conditions, oxidation of 1-acetylcyclohexene gave cyclohexanone as the major product due to the hydrolysis. It is also noticed that the internal double bond of limonene is readily oxidized, but the terminal one remains intact, i.e. 4isopropenyl-1-methyl-cyclohexane-1,2-diol was obtained as the only product. Under the similar reaction conditions, the vinyl group of 4-vinylcyclohexene did not undergo the oxidation (entry 4), neither the double bond of 1-hexene did (entry 9). This selectivity is presumably due to the electronic effect of $\mathrm{C}=\mathrm{C}$, which is similar to other related oxidation [15].

The stability and activity of the catalyst was tested in the recycle-use experiments. Typically, a mixture of cyclohexene $(5 \mathrm{mmol}), \mathrm{EO}_{45}-\mathrm{b}-\mathrm{MA}_{85}-\mathrm{Re}(5 \mathrm{mg})$ and $\mathrm{KHSO}_{5}$ $(10 \mathrm{mmol})$ in a mixture of ethyl acetate/water $(1: 1,20 \mathrm{~mL})$ was stirred at room temperature for $12 \mathrm{~h}$. After stop 
Table 4 Oxidation of cyclohexene by the recycle catalyst ${ }^{\mathrm{a}}$

\begin{tabular}{llllllll}
\hline Run & 1 & 2 & 3 & 4 & 5 & 6 & 7 \\
Yield (\%) & 100 & 96 & 100 & 100 & 97 & 98 & 95
\end{tabular}

${ }^{a}$ Reaction conditions: cyclohexene $(5 \mathrm{mmol}), \mathrm{KHSO}_{5}(10 \mathrm{mmol})$, catalyst $(5 \mathrm{mg})$, ethyl acetate $(10 \mathrm{~mL})$ and water $(10 \mathrm{~mL})$ at room temperature for $12 \mathrm{~h}$

stirring, the organic layer was separated. Another portion of substrate and oxidant in ethyl acetate was added to the aqueous residue for the next run. Over a period of seven reaction cycles under the same conditions, a minor leaching of metal ion was detected, but no significant loss of activity. The results are listed in Table 4 . By the analysis of ICP Mass, less than 5\% of rhenium was leached after seven runs. After the first run, a small portion of aqueous portion was dried under vacuum and the infrared spectrum of the residue was determined. The spectrum is much more complicated than the pre-catalyst. However, the absorptions corresponding to the $\mathrm{C}=\mathrm{O}$ stretching frequency $\left(1,645 \mathrm{~cm}^{-1}\right)$ and $\mathrm{C}=\mathrm{N}\left(1,540 \mathrm{~cm}^{-1}\right)$ appear in the spectrum, indicating that the copolymer remains intact during the catalysis.

Reaction mechanisms for epoxidation of an olefin catalyzed by methyltrioxorhenium complex have been proposed by Herrmann's and Espenson's groups. Pathways involve the direct oxidation of metal center to yield the corresponding monoperoxo or diperoxo species, which then undergo the oxygen transfer to yield the expoide [1619]. It is believed that the introduction of nitrogen donor ligand around the rhenium metal center would accelerate the catalytic reaction, which is presumably due to the stabilization of the intermediates via the coordination of $\mathrm{N}$ donor ligand toward metal ions [17]. Scheme 2 shows the possible reaction pathway for the bishydroxylation of olefin catalyzed by $\mathrm{EO}_{45}-\mathrm{b}-\mathrm{MA}_{85}-\mathrm{Re}$ system. The rhenium metal center plays the role for the oxidation. This initial oxidation results in the formation of epoxide, which is subsequently hydrolyzed by water under acidic conditions to yield the trans-diol.

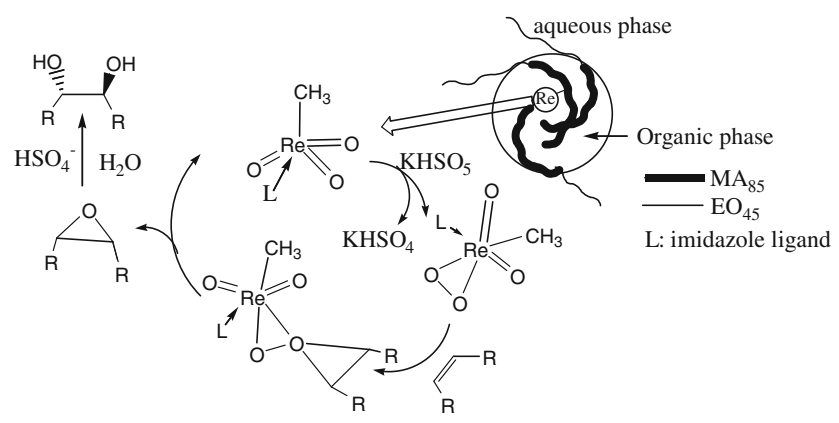

Scheme 2
In the $\mathrm{EO}_{45}-\mathrm{b}-\mathrm{MA}_{85}$-I system, the hydrophobic core provides a favorable environment for the metal complex through a coordination or chelation, which prevents the leaching of metal ion from the organic phase. Indeed, less than $5 \%$ loss of rhenium metal ions was observed after seven recycle-runs. The other advantage of this oxidation process is the use of potassium hydrogen peroxysulfate $\left(\mathrm{KHSO}_{5}\right)$ (known as Oxone), a commercial available chemical, which also provides an acidic medium during the reaction.

\section{Conclusion}

In conclusion, this procedure offers several advantages for the preparation of diols from the corresponding olefins such as low loading of catalyst, mild conditions, high yields, and clean reactions, which make it a useful and attractive methodology for organic synthesis. The simple workup procedure is also beneficial to this method. Further applications of this catalyst to other transformations are currently under investigation.

Acknowledgment We thank the National Science Council (NSC962113-M-002-009) for financial support.

\section{References}

1. Dwars T, Paetzold E, Oehme G (2005) Angew Chem Int Ed 44:7174

2. Kobayashi S, Manabe K (2002) Acc Chem Res 35:209

3. Toy PH, Janda KD (2000) Acc Chem Res 33:546

4. Leadbeater NE, Marco M (2002) Chem Rev 102:3217

5. Chen S, Janda KD (1997) J Am Chem Soc 119:8724

6. Mutter M, Hagenmaier H, Bayer E (1971) Angew Chem Int Ed Engl 10:811

7. Knapen JWJ, Vandermade AW, Dewilde JC, van Leeuwen PWNM, Wijkens P, Grove DM, van Koten G (1994) Nature 372:659

8. Chan YT, Lin HP, Mou CY, Liu ST (2002) Chem Commun 2878

9. Lin CH, Lin HP, Mou CY, Liu ST (2006) Microporous Mesoporous Mater 91:151

10. Ke IS, Liu ST (2007) Appl Catal A Gen 317:91

11. Pyun J, Matyjaszewski K (2001) Chem Rev 101:2921

12. Nunes CD, Pillinger M, Valente AA, Gonçalves IS, Rocha J, Ferreira P, Kühn FE (2002) Eur J Inorg Chem 1100

13. Matsumoto K, Sato Y, Shimojo M, Hatanaka M (2000) Tetrahedron:Asymmetry 11:1965

14. Saladino R, Andreoni A, Neri V, Crestini C (2005) Tetrahedron 61:1069

15. Wilson CW, Shaw PE (1973) J Org Chem 38:1684

16. Kühn FE, Scherbaum A, Herrmann WA (2004) J Organomet Chem 689:4149

17. Kühn FE, Santos AM, Roesky PW, Herdtweck E, Scherer W, Gisdakis P, Yudanov IV, Valentin CD, Rôsch N (1999) Chem Eur J 5:3603

18. Gisdakis P, Antonczak S, Köstlmeier S, Herrmann WA, Rôsch N (1998) Angew Chem Int Ed 37:2211

19. Al-Ajlouni AM, Espenson JH (1995) J Am Chem Soc 117:9243 